\title{
Crítica social e participação política na internet
}

Heloisa Prates

\author{
CARLÓN, M.; FAUSTO NETO, A. (org.). \\ Las políticas de los internautas: \\ nuevas formas de participación. \\ Buenos Aires, La Crujía, 200 p., 2012.
}

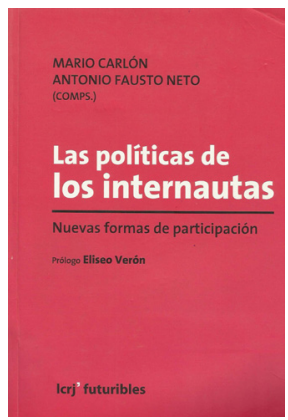

Resumo: Pesquisadores brasileiros, argentinos e espanhóis investigam as novas formas de participação política desencadeadas pelas plataformas digitais de comunicação. O debate pré-eleições em blogs, a utilização do Facebook por governantes, os coletivos e observatórios sociais e as revoluções creditadas às redes sociais são alguns dos temas discutidos na obra. Articulados em torno do conceito de midiatização, os textos propõem uma abordagem contextual da tecnologia e de suas apropriações.

Palavras-chave: midiatização; discurso; participação política; convergência digital; internet, redes sociais.

Abstract: Social criticism and political participation on the internet - Brazilian, Argentine and Spanish researches examine the new modes of political participation brought about by digital communications platforms. The pre-election debate in blogs, the use of Facebook by people in government, the social collectives and observatories and the revolutions credited to social network sites are some of the topics discussed in the book. Coordinated around the concept of mediatization, all the texts propose a contextual approach to technology and its appropriations.

Keywords: mediatization; discourse; political participation; digital convergence; internet; social network sites. 
Mais do que a comunicação digital sugerida pelo título da obra, o conceito de midiatização pode ser visto como eixo articulatório de Las políticas de los internautas: nuevas formas de paticipación, coletânea de nove artigos organizada por Mario Carlón e Antonio Fausto Neto. Isso não significa que seus autores ofereçam uma definição clara, unívoca ou consensual desse conceito. A midiatização coloca-se, antes, como uma postura epistemológica, um modo de olhar para a comunicação, uma tentativa de transcender a ideia de mediação entre dois polos (sejam eles emissores e receptores, indivíduo e sociedade ou quaisquer outros tradicionalmente apresentados numa relação direta). Inspirados nos trabalhos do pesquisador argentino Eliseo Verón, os autores desse livro buscam compreender os processos comunicacionais num contexto de inter-relação entre atores sociais, instituições e mídias. A ênfase certamente recai sobre o último desses três elementos: para Verón, as sociedades pós-industriais podem ser compreendidas como "sociedades nas quais as práticas sociais (modalidades de funcionamento institucional, mecanismos de tomada de decisão, hábitos de consumo, condutas mais ou menos ritualizadas, etc.) se transformam pelo fato de que há mídias" (VERÓN, 1992, p.124).

A midiatização leva em conta um princípio de produção técnica-tecnológica das mensagens (VERÓN, 1997, p. 12), qualificativo que contribui para sua especificação e para o estabelecimento de relações próprias do campo midiático. As relações instituídas nesse campo influenciam sobremaneira o contexto social, os modelos comportamentais e a produção de sentidos compartilhados para uma dada realidade. Com a emergência da rede mundial de computadores (a web), as condições de produção e de circulação de mensagens vêm mudando radicalmente: atores individuais têm crescente acesso à discursividade mediática, provocando revisões naquelas relações instituídas com base na comunicação broadcast. Verón, que assina o prólogo do livro, lança um desafio: gerar reflexões e polêmicas sobre o atual estado de midiatização da sociedade, no qual as tecnologias de comunicação em rede, instantâneas e disponíveis a milhões de atores individuais e coletivos, configuram emergências, apropriações e novas práticas políticas.

Pesquisadores brasileiros, argentinos e espanhóis assumiram esse desafio. Eles apresentam estudos de casos nos quais internautas ou personalidade políticas se apropriam das plataformas digitais de comunicação. As análises partem de eventos de grande repercussão midiática em diferentes contextos - três artigos voltam-se ao Brasil, três deles à Argentina, um à Espanha e os outros dois às revoluções no Oriente Médio e no norte da África, que ganharam da mídia a discutível alcunha de Primavera Árabe.

O primeiro artigo, de Antonio Fausto Neto, estuda a repercussão do "caso Kehl" demissão da colunista (e psicanalista) Maria Rita Kehl de O Estado de S.Paulo - na web: a reação dos internautas em sites, blogs e listas de discussões transformou-se numa análise do fazer jornalístico, do papel dos colunistas e do status de mediador do jornal. De certa forma, a web colocou o jornalismo no divã, ironiza o autor, fazendo menção à formação profissional de Kehl. 
No texto seguinte, José Luiz Braga investiga os circuitos comunicacionais, seus fluxos contínuos (o processo de passar uma informação adiante) e seus contrafluxos de retorno; a partir do Observatório da Imprensa, veículo dedicado à crítica da mídia, aprofunda-se uma reflexão sobre a importância da coordenação interna de coletivos de crítica social, da articulação entre instituições ou grupos similares, dos processos de divulgação e visibilidade, entre outras estratégias fundamentais para a consolidação de fluxos de comunicação efetivos, com potencial transformador.

Também voltado ao contexto brasileiro, o artigo de Maria das Graças Pinto Coelho e Anna Karinna Dantas Bevilaqua discute os blogs políticos e a promessa de ampliação do debate público nesses ambientes de comunicação digital; o blog Território Livre, que alcançou relativo sucesso no Rio Grande do Norte durante as eleições de 2010, permitiu a identificação de posturas participativas e colaborativas dos internautas. Mas, na visão das autoras, essas posturas recaem, em grande parte das interações, na personalização do debate (os atores sobrepõem-se aos argumentos) e, portanto, não foram suficientes para validar uma perspectiva de participação democrática e plural.

Os três artigos dedicados ao contexto argentino são assinados por Luis García Fanlo, Ana Slimovich e Mario Carlón. Fanlo analisa a convergência digital proposta pelos grandes grupos de mídia. No caso estudado, o uso do Twitter, durante o reality-show Gran Hermano 2.0 (equivalente ao Big Brother Brasil), capitaneado pelos produtores do programa, abriu espaço para uma rebelião dos ciberfãs: interferências nas votações e até mesmo a volta de um participante que havia sido eliminado da competição estão entre os feitos dos twitteiros e demonstram uma transformação dos sujeitos telespectadores.

Slimovich, por sua vez, investiga a utilização do Facebook por Cristina Kirchner, presidente da Argentina, e por Mauricio Macri, prefeito de Buenos Aires e principal nome da oposição ao governo Kirchner. Mario Carlón realiza uma interessante comparação entre a cobertura televisiva e o discurso dos usuários do Facebook durante a votação da lei do casamento igualitário no país. A convergência comparece como fator de grande relevância para a compreensão das novas práticas comunicacionais. Grandes grupos de comunicação, telespectadores-internautas e instituições políticas se inter-relacionam na produção do conteúdo mediático. Ao mesmo tempo que senadores, favoráveis e contrários à lei, concediam entrevista ao canal $C 5 N$; a emissora veiculava, na parte inferior da tela, os comentários dos internautas em suas páginas do Facebook. "Ver uma transmissão convergente nos faz lembrar, o tempo todo, que o discurso dos meios massivos não é o único" (CARLON, 2012, p.191), destaca Carlón.

Completam o livro o artigo de Jairo Ferreira e Paula Daibert sobre a plataforma Sharek.aljazeera.com; a investigação sobre o uso da web 2.0 nas eleições catalãs, assinada por Charo Lacalle; e o artigo de Sandra Valdettaro sobre a fusão e o contágio que criam as massas e produzem revoluções - estes encontrariam, na midiatização atual, sua condição de produção. A autora analisa as revoltas na Tunísia, na Moldávia, no Egito e outras revoltas que ficaram conhecidas como "revoluções das redes sociais". 
A abordagem contextual, que evita o determinismo tecnológico e ameniza as tendências tecnoufanistas muito comuns em análises da web, é um dos grandes méritos dessa obra. O conceito de midiatização, ao se interessar pelas inter-relações entre a mídia, as instituições políticas e os indivíduos e os grupos sociais, exige que sejam consideradas as interferências e interpenetrações dos discursos e práticas de cada um desses campos. A pertinência das análises, entretanto, é ofuscada, em alguns momentos, por uma falta de clareza metodológica - se há textos nos quais a fonte dos conteúdos analisados (sites, blogs, plataformas de relacionamento, etc.), a forma de seleção e os processos de investigação ficam bastante claros, há outros em que o leitor tem a impressão de que os exemplos foram selecionados subjetivamente a partir do vasto conteúdo disponível na web sobre o caso abordado.

O desafio de estabelecer recortes e, assim, interromper o fluxo de comunicação sobre aquilo que se quer estudar, que em momentos particulares se faz notar nesse livro, é o desafio de muitos pesquisadores que se dedicam à compreensão da comunicação digital. Há uma abundância de mensagens que circulam de diferentes maneiras, são modificadas, revisadas, parodiadas e produzem efeitos de sentidos dos mais variados. O atual estágio da midiatização requer, como propõe Verón, reflexões e polêmicas, tensionamentos e revisão de conceitos e métodos para que a pesquisa científica consiga apreender processos de tal maneira intensos, fugazes e múltiplos em suas acepções.

Heloisa Prates Pereira é jornalista e professora do Departamento de Comunicação das Faculdades Integradas Alcântara Machado (FIAM-FAAM). É doutoranda no Programa de Estudos Pós-Graduados em Comunicação e Semiótica da PUC-SP.

heloisa_p_pereira@hotmail.com

\section{Referências}

VERÓN, Eliseo. Interfaces: sobre la democracia audiovisual avanzada. In: FERRY, Jean-Marc et all. El nuevo espacio público. Barcelona: Ed. Gedisa, 1992, p. 124-139.

Esquema para el análisis de la mediatización. Diálogos de la comunicación, n. 48. Lima: Felafacs, 1997, p. 9-17. 